Article

\title{
Theoretical investigation of the mechanism of ethylene polymerization with salicylaldiminato vanadium(III) complexes
}

\author{
Yongxia Wang a, Minghui Zuo b, Yuesheng Li a,c,* \\ a State Key Laboratory of Polymer Physics and Chemistry, Changchun Institute of Applied Chemistry, Chinese Academy of Sciences, Changchun 130022, \\ Jilin, China \\ ${ }^{\mathrm{b}}$ College of Chemistry and Chemical Engineering, Mudanjiang Normal University, Mudanjiang 157012, Heilongjiang, China \\ c School of Material Science and Engineering, Tianjin University, Tianjin 300072, China
}

\section{A R T I C L E I N F O}

\section{Article history:}

Received 7 November 2014

Accepted 12 December 2014

Published 20 April 2015

\section{Keywords:}

Quantum chemistry calculation

Density functional theory

Olefin polymerization

Vanadium

Catalytic mechanism

\begin{abstract}
A B S T R A C T
The use of vanadium-based catalysts allows the preparation of high molecular mass polymers with uniform molecular mass distributions, polypropylene and ethylene/ $\alpha$-olefin copolymers with high $\alpha$-olefin incorporation. However, the design of ligand systems with vanadium catalysts would face difficulties, because it is difficult to experimentally determine the structures of the active species of vanadium catalysts. In this paper, possible structural candidates for the active species in ethylene polymerization catalyzed by the salicylaldiminato vanadium complex combined with $\mathrm{AlEt}_{2} \mathrm{Cl}$ were investigated using density functional theory. By comparing theoretical simulation results with previous experimental investigations, especially regarding the crucial role of the diethyaluminum chloride $\left(\mathrm{AlEt}_{2} \mathrm{Cl}\right)$ cocatalyst, it was concluded that a neutral bimetallic species containing two $\mathrm{Al}-\mathrm{Cl}-\mathrm{V}$ bridging bonds is the most favorable structure model for the active vanadium species. A notable effect of Al co-catalysts was clarified in the theoretical investigation. During the formation of the active species, $\mathrm{AlEt}_{2} \mathrm{Cl}$ act as an assistant for the alkylation and alkyl abstract processes of precursors. More importantly, $\mathrm{AlEt}_{2} \mathrm{Cl}$ is necessary for the formation of the bis(chlorine-bridged) structure in the active species, which showed a notable effect on the structural stability of the active species and its catalytic activity. Additionally, we investigated the chain termination mechanism in this system.
\end{abstract}

(C) 2015, Dalian Institute of Chemical Physics, Chinese Academy of Sciences. Published by Elsevier B.V. All rights reserved.

\section{Introduction}

Since the pioneering work of Ziegler and Natta [1,2] in the 1950 s, transition metal catalysts for olefin polymerization have attracted considerable interest, largely because of their various application in industrial processes. Among the transition metal catalysts, vanadium-based catalysts exhibit unique characteristics for the synthesis of high molecular mass polymers with uniform molecular mass distributions [3-5], and they are also efficient catalysts for synthesizing syndiotactic polypropylene [6-8] and ethylene/ $\alpha$-olefin copolymers with high $\alpha$-olefin incorporation [9-12]. Hence, numerous experimental investigations have been reported for the design of ligand systems with vanadium catalysts [13-21]. The main disadvantage of vanadium catalysts is deactivation associated with the reduction to low-valent, less active, or inactive species during catalysis [22-24]. Moreover, because of the unpaired electrons in V(II), V(III), and V(IV) complexes, it is difficult to experimentally de-

\footnotetext{
* Corresponding author. Tel: +86-431-85262124; Fax: +86-431-85262039; E-mail: ysli@ciac.ac.cn This work was supported by the National Natural Science Foundation of China (21104081 and 21234006). 
termine the structures of the active species of vanadium catalysts. Investigation of olefin polymerization mechanisms by vanadium catalysts, especially the formation of the active species, is still a scientific challenge.

Recent progress in computational chemistry has shown that it is an efficient tool to investigate kinetic mechanisms and the thermodynamic properties of transition metal reactions [25-28]. Many theoretical investigations of olefin polymerization mechanisms involving transition metals have been reported, using $a b$ initio [29,30], semiempirical [31,32], density functional theory (DFT) $[26,33,34]$, and molecular mechanics methods [29,35]. Among these methods, DFT has become the preferred method for electronic structure theory of complicated reaction systems, such as organic reactions, in part because of its optimal balance of reasonable accuracy and modest computational cost. Some theoretical investigations of vanadium catalytic systems have been reported. For example, Bühl [36] carried out a DFT study of ethylene insertion into V-C bonds to help experimentally modify (arylimido)vanadium (V) species to obtain catalysts for ethylene polymerization. Zambelli and coworkers [16] investigated the syndiotactic-specific polymerization of propylene with single-site catalysts, and several proposed active species and an olefin insertion mechanism involving vanadium were investigated with DFT calculations.

Our group previously synthesized a series of vanadium(III) catalysts bearing salicylaldiminato ligands $[\mathrm{RN}=\mathrm{CH}(\mathrm{ArO})] \mathrm{VCl}_{2}-$ (THF) 2 (Fig. 1) that showed high catalytic activity not only for ethylene homopolymerization but also for the copolymerization of ethylene with $\alpha$-olefin in the presence of $\mathrm{AlEt}_{2} \mathrm{Cl}[18,20]$. However, subsequent modification of this catalytic system and establishing the structure-reactivity relationship are difficult experimentally because of the lack of precise information about the nature of the catalytically active species and the elementary reactions. In this paper, we clarified in detail the mechanism of ethylene polymerization catalyzed by salicylaldiminato V(III) complexes based on DFT investigations. For the calculations, $\left[\mathrm{C}_{6} \mathrm{H}_{5} \mathrm{~N}=\mathrm{CH}\left(\mathrm{C}_{6} \mathrm{H}_{4} \mathrm{O}\right)\right] \mathrm{VCl}_{2}(\mathrm{THF})_{2}(\mathbf{2 a}, \mathbf{1})$ was chosen as the model compound to explore the active form. Optimized structure $\mathbf{1}$ agreed well with the molecular structure obtained via X-ray crystal analysis. Our research aimed to understand (1) possible models for the vanadium active species, (2) the involved olefin polymerization mechanism, and (3) the most favorable chain termination pathway.

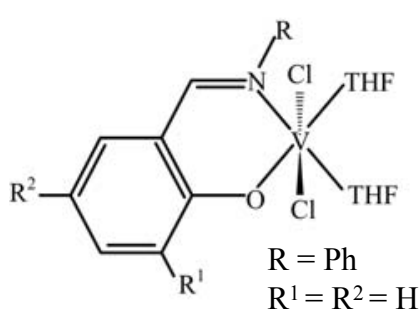

$1 \mathrm{a}-1 \mathrm{k}$

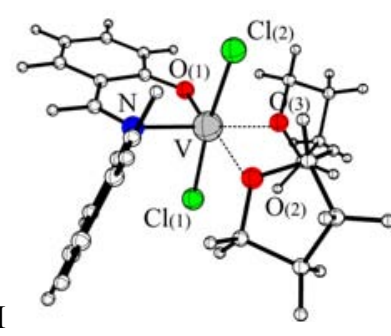

1
Fig. 1. Series of salicylaldiminato vanadium catalysts (left) and optimized geometry of $\mathbf{1}$ (right).

\section{Computational details}

DFT calculations were performed using the Amsterdam Density Functional program [37], which has been shown to be suitable for calculating structure and vibrational model for large systems, and especially for treating complexes containing transition metals. Unrestricted spin-treatment was used for all calculations. All of the structure calculations were based on the Becke-Perdew exchange-correlation functional [38,39]. A triple Slater-type orbital (STO) basis set was used for V, while all other atoms were described by a double- $\zeta$ plus polarization STO basis. The $1 s^{2} 2 s^{2} 2 p^{6}$ configuration on vanadium and chlorine, and the $1 \mathrm{~s}^{2}$ configuration on carbon, nitrogen, and oxygen were assigned to the core and treated by the frozen-core approximation. The structure of transition states was obtained by full transition-state optimizations based on linear transit calculations. First, along the stepwise decreasing reaction coordinates, all variables except for the reaction coordinate bond of the structures were optimized. Then, the maximum of this linear transit was used as the starting structure in the full transition-state optimization without any geometry constraints. For the ethylene insertion reaction, the reaction coordinate was chosen as the formation of the new $\mathrm{C}-\mathrm{C}$ bond between the ethylene monomer and the polymer chain on the catalyst vanadium center.

To obtain more accurate activation energy of propagation and chain transfer steps in this catalytic system, single-point calculations were carried out using the M06-L functional [40] based on structure optimized by BP86 functional calculations. Solvent effects were estimated based on the gas-phase geometries with the conductor-like screening model (COSMO). A dielectric constant of 2.38 was chosen to represent toluene as the solvent. The atomic radii used were $0.19,0.23,0.13,0.14,0.23$, and $0.116 \mathrm{~nm}$ for $\mathrm{V}, \mathrm{Al}, \mathrm{O}, \mathrm{N}, \mathrm{C}$, and $\mathrm{H}$, respectively. For comparison, single-point calculations were also performed using the B3LYP-D3 functional [41]. The M06-L and B3LYP-D3 SCF energy were calculated with an all-electron TZP basis set for $\mathrm{V}$ and an all-electron DZP basis set for all other atoms.

\section{Results and discussion}

\subsection{Model for vanadium active species}

To determine the ground states of the salicylaldiminato vanadium system, unrestricted calculations for the singlet and triplet states of catalysts $\mathbf{2 a}(\mathbf{1}), \mathbf{2 b}, \mathbf{2 e}$, and $\mathbf{2} \mathbf{f}([\mathrm{RN}=\mathrm{CH}(\mathrm{ArO})]-$ $\mathrm{VCl}_{2}(\mathrm{THF})_{2}, \mathrm{Ar}=\mathrm{C}_{6} \mathrm{H}_{4}, \mathrm{R}=\mathrm{Ph}, \mathbf{2 a} ; \mathrm{R}=p-\mathrm{CF}_{3} \mathrm{Ph}, \mathbf{2 b} ; \mathrm{R}=2,6-$ $i \mathrm{Pr}_{2} \mathrm{Ph}, 2 \mathrm{e} ; \mathrm{R}=$ cyclohexyl, 2f) were performed. The results showed that the singlet state of $\mathbf{2 a}$ was $9.3 \mathrm{kcal} / \mathrm{mol}$ higher in energy than the triplet state, and changing the ligands does not change this trend (the energy differences of $\mathbf{2 b} \mathbf{b} \mathbf{2} \mathbf{e}$, and $\mathbf{2} \mathbf{f}$ were $9.2,9.8$, and $9.5 \mathrm{kcal} / \mathrm{mol}$, respectively). As a result, it can be concluded that the ground state of this series of salicylaldiminato vanadium catalysts is the triplet state.

Table 1 shows the calculated bond lengths (pm) and angles $\left({ }^{\circ}\right)$ around the vanadium center of $\mathbf{2 a}$ compared with the structure obtained by X-ray crystallographic analysis in a pre- 
Table 1

Optimized bond lengths and angles around the vanadium center of $\mathbf{2 a}$.

\begin{tabular}{lrcr}
\hline & \multicolumn{3}{c}{ Bond distances (pm) } \\
\cline { 2 - 4 } & Singlet & DFT & Exp. $^{\text {a }}$ \\
\hline $\mathrm{V}-\mathrm{N}(1)$ & 201.63 & 204.93 & 210.99 \\
$\mathrm{~V}-\mathrm{O}(1)$ & 187.50 & 189.38 & 186.84 \\
$\mathrm{~V}-\mathrm{O}(3)$ & 220.61 & 221.70 & 211.40 \\
$\mathrm{~V}-\mathrm{Cl}(1)$ & 233.82 & 234.51 & 236.39 \\
\hline & \multicolumn{3}{c}{ Bond angles $\left(^{\circ}\right)$} \\
& Singlet & DFT & Exp. $^{\mathrm{a}}$ \\
\hline $\mathrm{O}(1)-\mathrm{V}-\mathrm{O}(3)$ & 87.38 & 87.59 & 87.08 \\
$\mathrm{O}(1)-\mathrm{V}-\mathrm{N}(1)$ & 89.75 & 89.79 & 89.58 \\
$\mathrm{O}(1)-\mathrm{V}-\mathrm{Cl}(1)$ & 94.38 & 94.63 & 92.70 \\
$\mathrm{O}(2)-\mathrm{V}-\mathrm{O}(3)$ & 82.73 & 83.76 & 89.71 \\
$\mathrm{~N}(1)-\mathrm{V}-\mathrm{Cl}(1)$ & 91.64 & 90.63 & 94.13 \\
$\mathrm{Cl}(1)-\mathrm{V}-\mathrm{Cl}(2)$ & 170.00 & 170.57 & 174.75 \\
\hline
\end{tabular}

a From the experimental investigation [18].

vious experimental investigation [18]. The optimized bond lengths agree well with the experimental structural information. The calculated bond angles are accurate for the framework of the catalyst, while the results for bond angles involving oxygen atoms of THF ligands $(\mathrm{O}(2)$ and $\mathrm{O}(3))$ are less accurate. The calculation methods used in this paper provide a reasonably accurate description for this series of vanadium catalysts.

The generally accepted mechanism for homogeneous polymerization catalysis is the Cossée-Arlman mechanism [42]. Without considering the influence of the cocatalyst, the insertion of olefin into the metal-carbon bond of the active species is usually described as a two-step process: monomer uptake and insertion. The uptake involves $\pi$-complexation of the monomer to the metal center, and the insertion goes through a transition state with a four-membered ring structure. Additionally, during the polymerization catalysis, the cocatalyst usually has two roles in the activation step: to alkylate the metal complex and then to abstract one of the alkyl groups to form an active species $[43,44]$.

For the $\left[\mathrm{C}_{6} \mathrm{H}_{5} \mathrm{~N}=\mathrm{CH}\left(\mathrm{C}_{6} \mathrm{H}_{4} \mathrm{O}\right)\right] \mathrm{VCl}_{2}(\mathrm{THF})_{2}$ complex, AlEt ${ }_{2} \mathrm{Cl}$ was required to achieve high catalytic activity. Other organoaluminum compounds, such as modified methylaluminoxane (MAO), dry MAO, AlMe3, and AlEt3, have been proven to be inefficient for ethylene polymerization [27]. Therefore, we carried out theoretical investigations to determine the role of the cocatalyst in ethylene polymerization on the vanadium complex, as shown in Scheme 1.

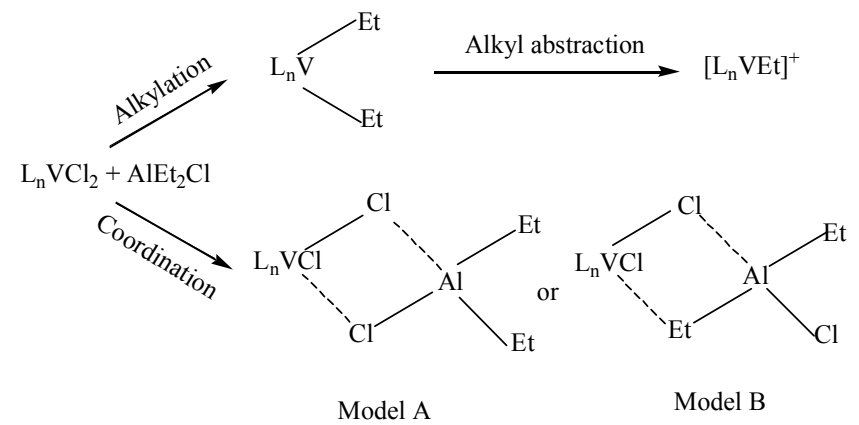

Scheme 1. Possible assistance mechanisms of $\mathrm{AlEt}_{2} \mathrm{Cl}$ for the formation of active species.
If the true active species is assumed to be a cationic species, our theoretical results showed that the activation steps using different organoaluminum compounds showed similar energy profiles, not only in the alkylation process but also in the alkyl abstract process. This inconsistency between the theoretical and experimental results led us to hypothesize that $\mathrm{AlEt}_{2} \mathrm{Cl}$ has another crucial effect on the generating progress of real active species: forming bridge-linked complexes. When $\mathrm{AlEt}_{2} \mathrm{Cl}$ approaches the metal center, one chlorine atom of the vanadium precursor can be protected by forming $\mathrm{Al}-\mathrm{Cl}-\mathrm{V}$ bridging bonds before the alkylation reaction. The calculations indicated that the formation of two Al-Cl-V bridging bonds in model $\mathrm{A}$ and one in model B (Scheme 1) are exothermic reactions (ca. 34 and $31 \mathrm{kcal} / \mathrm{mol}$, respectively). As described in Scheme 1, the $\mathrm{Al}-\mathrm{Cl}-\mathrm{V}$ and $\mathrm{Al}-\mathrm{C}-\mathrm{V}$ bridging bonds in model $\mathrm{B}$ can also occur in the presence of $\mathrm{AlMe}_{3}, \mathrm{AlEt}_{3}, \mathrm{Al}^{i} \mathrm{Bu}_{3}$, or MAO. However, the role of $\mathrm{AlEt}_{2} \mathrm{Cl}$ in the formation of two $\mathrm{Al}-\mathrm{Cl}-\mathrm{Vl}$ bridging bonds in model $\mathrm{A}$ is crucial because of the lack of chlorine atoms in the other organoaluminum compound. From the point of view of consistency with experiments, model A is obviously more reasonable than model B. The real structure of the active species in model A used for the calculation of the ethylene insertion mechanism is called $\mathbf{a 1}$.

Despite the crucial role of $\mathrm{AlEt}_{2} \mathrm{Cl}$, there are other possible models for the vanadium active species. Thus, we also investigated the formation of several other active species and their catalytic mechanisms for ethylene polymerization, and compared these with bimetallic species a1 to confirm the assumption that the active species is cationic. Scheme 2 shows the formation processes of active species $\mathbf{a} 1$ and other possible active species originating from vanadium complex $\mathbf{1}$ $\left(\mathrm{LVCl}_{2} \text { (THF) }\right)_{2}$, where $\mathrm{L}$ is the salicylaldiminato ligand). Precatalyst 1 contains four possible leaving groups: two chlorine atoms and two THF molecules. Linear transit simulations for the approach process of $\mathrm{AlEt}_{2} \mathrm{Cl}$ to $\mathbf{1}$ always led to the loss of one THF molecule to form complex $\mathrm{LVCl}(\mathrm{THF})_{2}$ (2) because the coordination space around the vanadium center of $\mathbf{1}$ is crowded. Evidently, complex $\mathbf{2}$ is electron deficient, so $\mathrm{AlEt}_{2} \mathrm{Cl}$ approaches the vanadium center from the coordination vacant site, forming bridge-linked complex [ $\left.\mathrm{LVCl}_{3}(\mathrm{THF})\right] \mathrm{AlEt}_{2}$ (3) or $\left[\mathrm{LVCl}_{2}\right.$ (THF)] AlEt $2 \mathrm{Cl}$ (4), whose structure contains two Al-Cl-V bridging bonds or one $\mathrm{Al}-\mathrm{Cl}-\mathrm{V}$ and one $\mathrm{Al}-\mathrm{C}-\mathrm{V}$ bridging bonds, respectively. The formation process of complex $\mathbf{3}$ was calculated to be exothermic by $33.7 \mathrm{kcal} / \mathrm{mol}$, while the formation process of complex 4 was exothermic by $30.6 \mathrm{kcal} / \mathrm{mol}$. It is noteworthy that the $\mathrm{Al}-\mathrm{C}-\mathrm{V}$ bridging bond is much weaker than the $\mathrm{Al}-\mathrm{Cl}-\mathrm{V}$ bridging bond, because the $\mathrm{Al}-\mathrm{C}$ distance of the $\mathrm{AlEt}_{2} \mathrm{Cl}$ moiety in $\mathbf{4}$ elongated by only $4.6 \mathrm{pm}$ compared with the free $\mathrm{AlEt}_{2} \mathrm{Cl}$ compound, while the $\mathrm{Al}-\mathrm{Cl}$ distance of the $\mathrm{AlEt}_{2} \mathrm{Cl}$ moiety in 3 elongated by $15.9 \mathrm{pm}$. Accordingly, complex 4 can also be considered to contain only one Al-Cl-V bridging bond, because the carbon bridging bond is easily broken to form one coordination vacant site.

The alkylation of the unbridged chlorine atom in complex 4 will give rise to active species $\mathbf{a} 3$, which can be seen as an exchange progress of the chlorine atom of $\mathbf{4}$ with the alkyl groups of $\mathrm{AlEt}_{2} \mathrm{Cl}$. As shown in Scheme 3, in the first step, $\mathrm{AlEt}_{2} \mathrm{Cl}$ coor- 


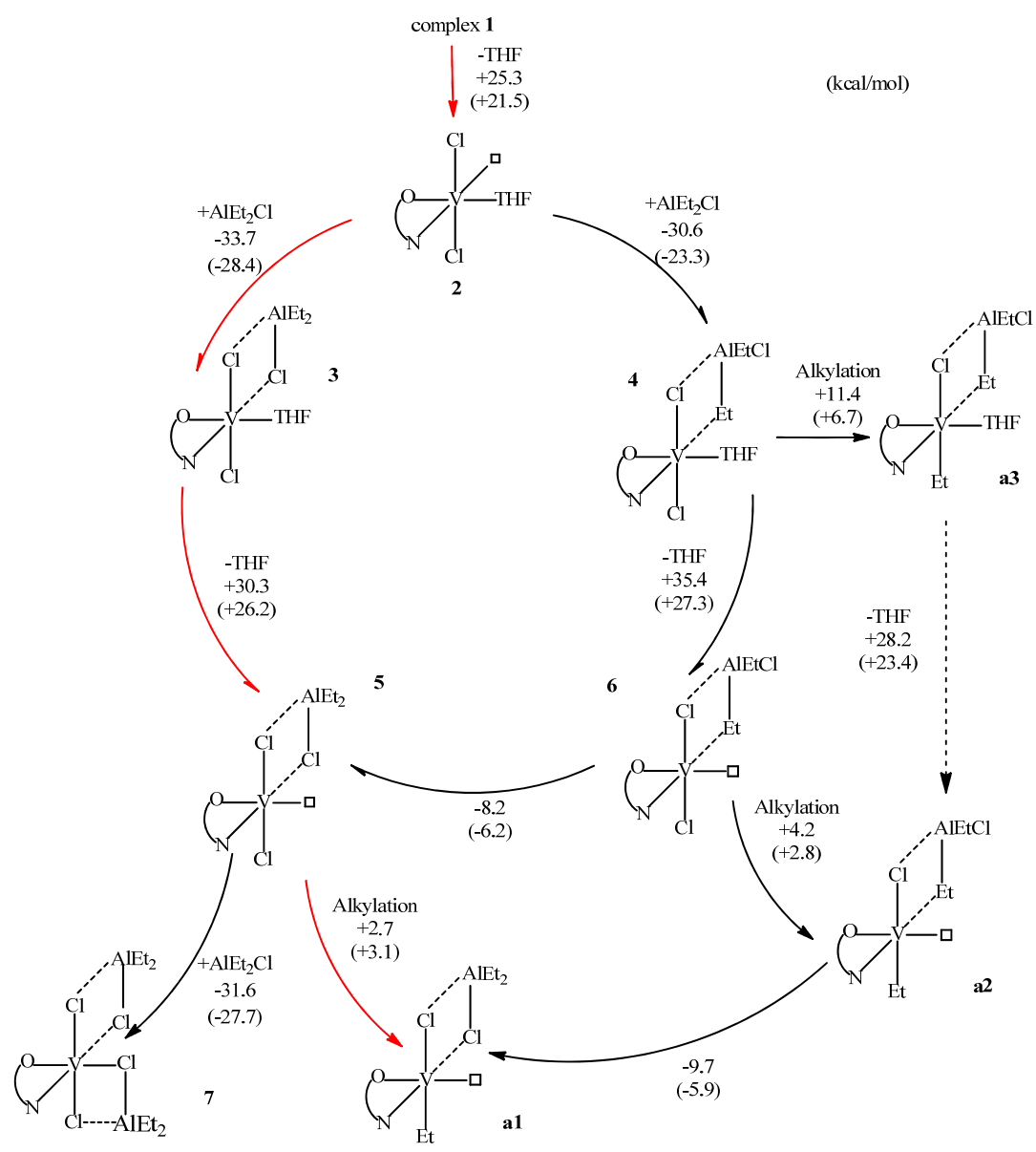

Scheme 2. Possible formation mechanism of bridge-linked complexes. The energy was calculated at the M06-L functional level, and the energy changes calculated at the B3LYP-D3 functional level are given in parentheses.

dinates to the vanadium center of $\mathbf{4}$ and forms a stable bimetallic complex, which is $18.7 \mathrm{kcal} / \mathrm{mol}$ more stable than the reactants. The following $\mathrm{AlEtCl}_{2}$ removal process is endothermic by $30.1 \mathrm{kcal} / \mathrm{mol}$. As a result, the overall alkylation reaction of 4 is endothermic by ca. $11.4 \mathrm{kcal} / \mathrm{mol}$. In contrast, without the loss of the THF molecule, the direct alkylation process of $\mathbf{3}$ is very difficult because the vanadium center of $\mathbf{3}$ is a stable six-coordinate form and is hardly accessible. Thus, the corresponding active species model was not considered via the direct alkylation of unbridged chlorine atom in complex $\mathbf{3}$.

From the results presented in the previous section, the loss of the THF molecule has to occur before alkylation of the unbridged chlorine atom in complex 3 can occur. This loss of the THF molecule from 3 is endothermic by $30.3 \mathrm{kcal} / \mathrm{mol}$, and gives rise to complex $\mathbf{5}$. Subsequently, alkylation of $\mathrm{LVCl}_{3}\left(\mathrm{AlEt}_{2}\right)$ (5) will give bimetallic species $\mathrm{LVCl}_{2} \mathrm{Et}\left(\mathrm{AlEt}_{2}\right)$ (a1), and the vanadium active species model presented in the previous section. Additionally, if another $\mathrm{AlEt}_{2} \mathrm{Cl}$ molecule coordinates to $\mathbf{5}$

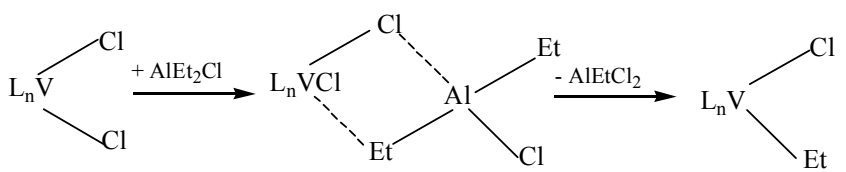

Scheme 3. Alkylation reaction of vanadium complex with cocatalyst $\mathrm{AlEt}_{2} \mathrm{Cl}$. with two $\mathrm{Al}-\mathrm{Cl}-\mathrm{V}$ bridging bonds, complex $\mathrm{LVCl}_{4}\left(\mathrm{AlEt}_{2}\right)_{2}$ (7) will form, which is inactive for olefin polymerization because of the lack of a vacant coordinate site and alkyl group. The formation of $\mathbf{7}$ may be a possible side reaction in this catalytic system and will decrease the catalytic activity of the vanadium catalyst.

Another possible active species LVClEt(AlEt ${ }_{2} \mathrm{Cl}$ ) (a2) can form following the route of $\mathbf{4} \rightarrow \mathbf{6} \rightarrow \mathbf{a} 2$ in Scheme 2. Similar to active species [LVClEt(THF)] $\mathrm{AlEt}_{2} \mathrm{Cl}$ (a3), the carbon bridging bond in $\mathbf{a} 2$ is weak and easily broken. Therefore, $\mathbf{a} 2$ and $\mathbf{a} 3$ can also be described as active species containing only one chlorine bridging bond, or even as intimate ion pairs. Comparing the energy profiles, there is no significant difficulty in the formation processes of neutral active species a1-a3. Additionally, the formation of chlorine bridging bonds in the active species benefits the structural stability, which is indicated by the high exothermicity in the coordination process of $\mathrm{AlEt}_{2} \mathrm{Cl}$ to the vanadium center.

The possible transformation reactions of three active species should be considered. As outlined in Scheme 2, active species a3 might transform to a2 through the loss of a THF molecule. If the $\mathrm{AlEt}_{2} \mathrm{Cl}$ moiety in $\mathbf{a} 2$ rotates to break the carbon bridging bond and forms a much stronger chlorine bridging bond, active species a1 will form with an exothermic energy of $9.7 \mathrm{kcal} / \mathrm{mol}$. The transformation process from a3 to $\mathbf{a} \mathbf{1}$ can 
also proceed via the intermediate $\left[\mathrm{LVCl}_{2} \mathrm{Et}(\mathrm{THF})\right] \mathrm{AlEt}_{2}$, which is formed when the $\mathrm{AlEt}_{2} \mathrm{Cl}$ moiety in $\mathbf{a} 3$ rotates to form the structure containing two $\mathrm{Al}-\mathrm{Cl}-\mathrm{V}$ bridging bonds.

From an energetic point of view, the main difficulty in the formation of neutral active species a1-a3 is the dissociation processes of one or two THF molecules from the vanadium center of the catalyst. Nevertheless, this dissociation process of THF may be facilitated by the energy released by $\mathrm{AlEt}_{2} \mathrm{Cl}$ coordination to the vanadium center, especially considering that a high $\mathrm{AlEt}_{2} \mathrm{Cl}$ concentration is necessary to obtain high catalytic activity in the experimental investigation.

As mentioned above, an important role of organoaluminum compounds is to alkylate the catalyst precursor and abstract one alkyl group to give the cationic active species (see Schemes 1 and 4). As shown in Scheme 4, the alkylation of two chlorine atoms in $\mathbf{2}$ will produce complex LVEt 2 (THF) (8). Additionally, the THF group of $\mathbf{8}$ can be easily lost to give complex LVEt$_{2}(\mathbf{9})$. However, subsequent alkyl abstract reactions of $\mathbf{8}$ and $\mathbf{9}$ are strongly energetically unfavorable from our theoretical results, which may be the main difficulty that needs to be overcome to form cationic active species [LVEt(THF)] ${ }^{+}$(a4) and (LVEt) ${ }^{+}$ (a5). The process of $\mathrm{AlEt}_{2} \mathrm{Cl}$ abstracting one alkyl group from complex 8 is strongly endothermic by $31.5 \mathrm{kcal} / \mathrm{mol}$ owing to the electron deficient nature of complex 8 , and the alkyl abstraction process of complex $\mathbf{9}$ needs even more energy (54.8 $\mathrm{kcal} / \mathrm{mol}$ ). These theoretical results indicate that the formation of cationic active species $\mathbf{a} 4$ and $\mathbf{a 5}$ is much more difficult than the formation of neutral active species.

Complexes 8 and 9 both have alkyl groups and vacant sites, which are necessary for olefin insertion. Thus, they can also be seen as possible stable active species because the subsequent alkyl abstraction processes of complexes $\mathbf{8}$ and $\mathbf{9}$ are difficult. However, further calculations indicated that the cleavage of a THF molecule is always accompanied by the coordination of ethylene to the vanadium center of complex $\mathbf{8}$. Thus, complex $\mathbf{8}$ can be excluded as a possible stable active species. Accordingly, complex $\mathbf{9}$ is included as neutral active species $\mathbf{a} 6$ in the discussion about the mechanism of ethylene insertion.

In summary, we have investigated the formation process of possible vanadium active species for ethylene polymerization,

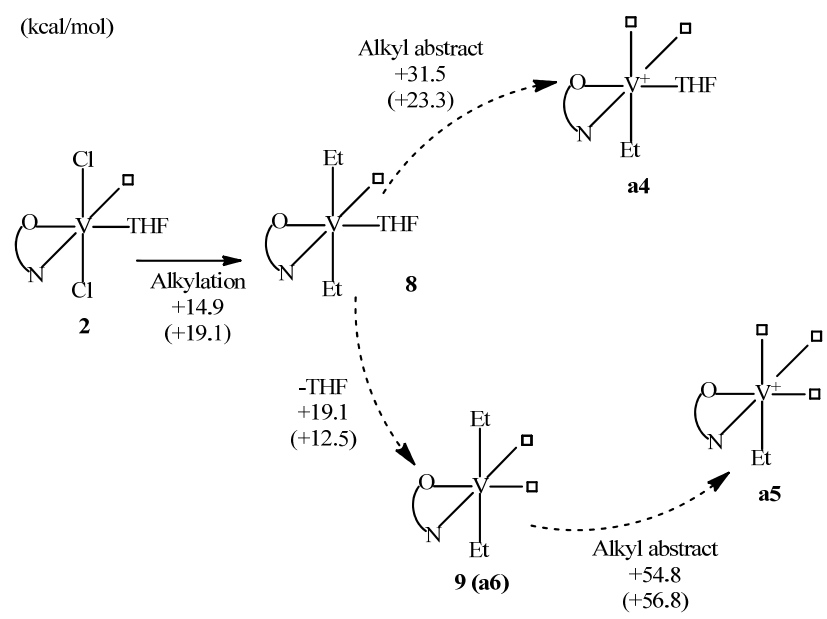

Scheme 4. Formation process of cationic active species.

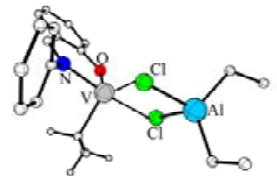

a1

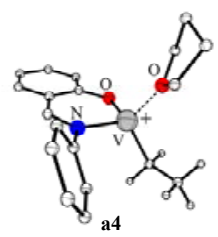

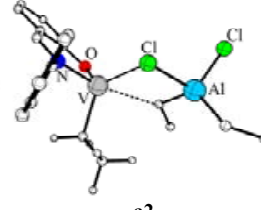

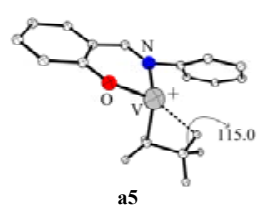

a5
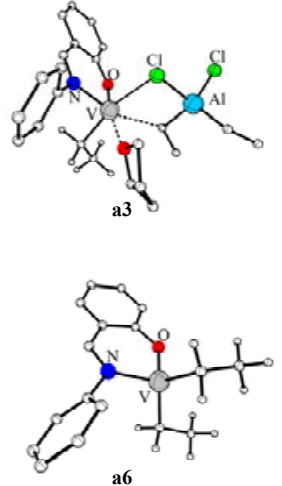

Fig. 2. Optimized geometries of active species a1-a6 (only relevant hydrogen atoms were shown).

and obtained six stable species: two cationic species (a4 and a5) and four neutral species (a1-a3 and a6). As discussed above, active species $\mathbf{a} 2$ and $\mathbf{a} 3$ can also be described as intimate ion pairs. The formation of cationic active species is much more difficult than the formation of neutral active species because of the very high energy required for the alkyl abstraction process. Accordingly, the relatively energetically favorable structure $\mathbf{a} 4$ was the only cationic active species that was further investigated for the ethylene insertion process, and it is compared with neutral active species a1. Optimized structures of all of the possible active species are shown in Fig. 2.

\subsection{Mechanism of ethylene polymerization}

Based on complex a1, we investigated the ethylene insertion process in the polymerization by following the well-established Cossée-Arlman mechanism. Theoretically, the ethylene coordination and insertion reaction can take place from several different directions because of the asymmetric structure of a1. However, linear transit calculations of each possible reaction pathway indicated that the attack of the incoming ethylene molecule was easiest at the trans position of the nitrogen atom. Fig. 3 shows the optimized structures of the $\pi$-complex and the transition state, and the potential energy surface of the dominant reaction pathway. In the first step, the incoming ethylene molecule coordinates to the vacant site in a1 forming $\pi$-complex C1, and this process is exothermic by $18.1 \mathrm{kcal} / \mathrm{mol}$. Subsequently, ethylene inserts into the vanadium-carbon bond via the four-membered cyclic transition state TS1, which has an activation energy barrier of $14.7 \mathrm{kcal} / \mathrm{mol}$ relative to the $\pi$-complex (the energy of TS1 is $-3.4 \mathrm{kcal} / \mathrm{mol}$ relative to the isolated reactants). The $\mathrm{C}_{\alpha}-\mathrm{H}$ distance in TS1 elongated to $113.8 \mathrm{pm}$, indicating a strong $\alpha$-agostic interaction. This $\alpha$-agostic interaction seems to facilitate the ethylene insertion reaction. The overall ethylene insertion reaction is a highly exothermic process ( $c a .27 .1 \mathrm{kcal} / \mathrm{mol}$ ), and insertion product $\mathbf{P 1}$ resembles the starting structure a1. Thus, the next ethylene coordinate and insertion reaction will take place to propagate the polymerization reaction.

To investigate the most likely active species for ethylene polymerization, we compared the different ethylene insertion 

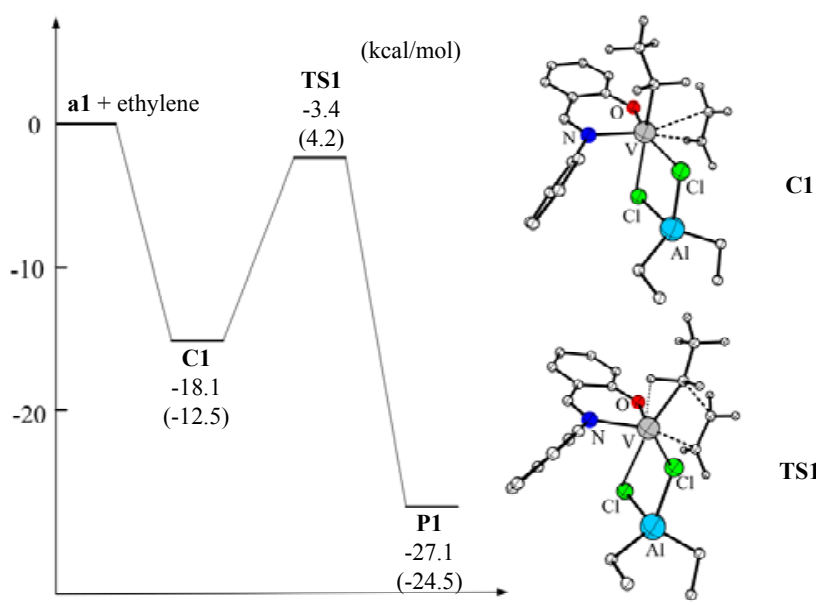

Fig. 3. Potential energy surface and optimized geometries of the $\pi$-complex and transition state of the ethylene insertion reaction catalyzed by active species a1. The energy was calculated at the M06-L functional level, with energy changes calculated at the B3LYP-D3 functional level given in parentheses.

pathways of the various active complexes. Table 2 shows the relative energy of each pathway. For cationic active species a4, the ethylene complexation process is less exothermic than that of $\mathbf{a 1}$, and the insertion barrier is higher than active species $\mathbf{a 1}$ by $5.7 \mathrm{kcal} / \mathrm{mol}$. On the whole, cationic active species $\mathbf{a} 4$ is not favorable over active species a1. Therefore, considering the very difficult formation process of active species a4, cationic species $\mathbf{a} 4$ can be ruled out as the most favorable active species in this catalytic system. Neutral active species a3 shows a similar ethylene insertion barrier to a1, but the ethylene complexation process of a3 is more difficult (exothermic by 13.0 $\mathrm{kcal} / \mathrm{mol}$ ). Furthermore, the insertion barrier of a1 ( $c$ a. 14.7 $\mathrm{kcal} / \mathrm{mol}$ ) is about $7 \mathrm{kcal} / \mathrm{mol}$ lower than that of $\mathbf{a} 2$ and about $10 \mathrm{kcal} / \mathrm{mol}$ lower than that of $\mathbf{a 6}$. As a whole, the much more facile ethylene coordination process and the lowest insertion barrier suggest that $\mathbf{a} \mathbf{1}$ is the active species. As a result, bimetallic species a1 should show higher catalytic activity for ethylene polymerization than the other possible active species. Mulliken charge analysis at the M06-L functional level shows that $\mathbf{a 1}$ has lower positive charges on the vanadium centre than the other possible active species (Mulliken charges of the $\mathrm{V}$ centre of $\mathbf{a 1}, \mathbf{a} 2, \mathbf{a} 3, \mathbf{a} 4$, and $\mathbf{a} 6$ are $1.45,1.65,1.61,1.77$, and 1.76 in atomic units). A reasonable explanation is that the less electrophilic $\mathrm{V}$ center of $\mathbf{a 1}$, which is generated by bridging the $\mathrm{AlEt}_{2} \mathrm{Cl}$ moiety, is most stable for the active species and the transition state, giving rise to enhanced catalytic activity.

Table 2

Calculated ethylene complexation and insertion energy barriers for five possible active species at the M06-L functional level (kcal/mol).

\begin{tabular}{|c|c|c|c|}
\hline Active species & $\pi$-Complex ${ }^{a}$ & Transition state $^{a}$ & Insertion barrier ${ }^{b}$ \\
\hline a1 & -18.1 & -3.4 & 14.7 \\
\hline a2 & -15.5 & 6.5 & 22.0 \\
\hline a3 & -13.0 & 1.2 & 14.2 \\
\hline a4 & -16.4 & 4.0 & 20.4 \\
\hline a6 & -11.5 & 12.8 & 24.3 \\
\hline
\end{tabular}

a Relative to the reactants. ${ }^{\mathrm{b}}$ Relative to $\pi$-complex.
The more facile formation process and higher catalytic activity for ethylene insertion of bimetallic species a1 compared with the other active species supports our hypothesis. At the same time, the crucial role of cocatalyst $\mathrm{AlEt}_{2} \mathrm{Cl}$ for active species a1 offers a more reasonable explanation of the experimental observation.

\subsection{Ligand effect}

Experimental investigation has shown that ligand modification has a significant effect on the catalytic behavior of this series of salicylaldiminato vanadium catalysts [26]. For example, introducing two ortho-isopropyl groups into the $\mathrm{N}$-aryl moiety of the ligand to form complex $\mathbf{2 e}$ increased the catalytic activity by about $10 \%$. In contrast, introduction of a nonconjugated substituent cyclohexyl into the N-moiety of the ligand decreased the catalytic activity of complex $\mathbf{2 f}$ by about $50 \%$ compared with complex 2a. Following the dominant reaction pathway of ethylene polymerization catalyzed by $\mathbf{2 a}$, ethylene insertion reactions with $\mathbf{2 e}$ and $\mathbf{2 f}$ were investigated. Table 3 shows the relative energy of each pathway. The calculated ethylene insertion barriers were in the order $\mathbf{2 e}<\mathbf{2 a}<\mathbf{2} \mathbf{f}$, which agrees with the order of the experimental catalytic activity of $\mathbf{2 e}>\mathbf{2 a}>\mathbf{2 f}$. This result is strong support for $\mathbf{a} \mathbf{1}$ being the active species.

The catalytic activity of complexes can be affected by various factors, such as reaction conditions, the formation processes of active species, and possible inactivation of active species. Thus, the real effect of ligands on the polymerization will be far more complex than the above comparison of the ethylene insertion barriers of $\mathbf{2 a}, \mathbf{2 e}$, and $\mathbf{2 f}$. Further studies, including a more detail investigation of the effect of ligand modification and its application to the synthesis of new vanadium catalysts, are underway.

\subsection{Chain transfer reactions}

Previous experimental investigations [18,20] have shown that the molecular mass of the polymer obtained from ethylene polymerization gradually decreases with increasing $\mathrm{AlEt}_{2} \mathrm{Cl}$ dosage. More importantly, NMR analysis shows that the end group of the polymer is saturated. These facts indicate that the dominant chain transfer reaction in this catalytic system is chain transfer to aluminum. In this section, the chain transfer reactions in ethylene polymerization catalyzed by active species a1 were investigated using DFT calculations to clarify the main factors determining the dominant chain transfer pathway. For comparison, the chain transfer reactions involved with cationic active species a4 were also investigated. Scheme 5

Table 3

Calculated ethylene complexation and insertion barriers for $\mathbf{2 a}, \mathbf{2 e}$, and $2 \mathbf{f}$ at the M06-L functional level ( $\mathrm{kcal} / \mathrm{mol})$.

\begin{tabular}{lccc}
\hline Active species & $\pi^{- \text {Complex }^{\mathrm{a}}}$ & Transition state $^{\mathrm{a}}$ & Insertion barrier $^{\mathrm{b}}$ \\
\hline $\mathbf{2 a}$ & -18.1 & -3.4 & 14.7 \\
$\mathbf{2 e}$ & -14.0 & -2.3 & 11.6 \\
$\mathbf{2 f}$ & -18.1 & -2.5 & 15.7 \\
\hline
\end{tabular}

a Relative to the reactants. ${ }^{b}$ Relative to $\pi$-complex. 
(1)
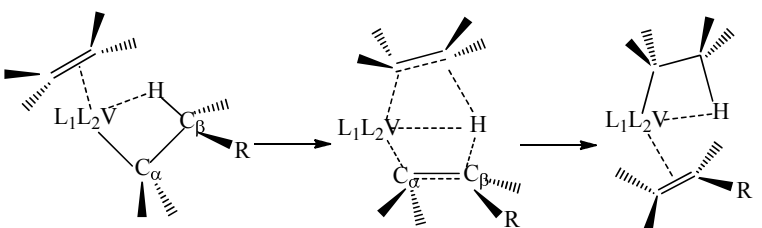

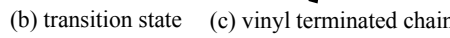

(2)

(a) $\pi$-complex<smiles>[R][C@H](C)C(C)C</smiles>

(a) $\beta$-agostic complex
(3)

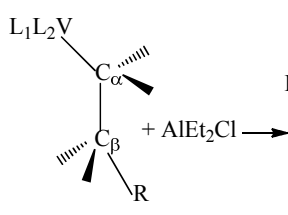

(a) $\alpha$-agostic complex
H (b) transition state

(c) vinyl terminated chain
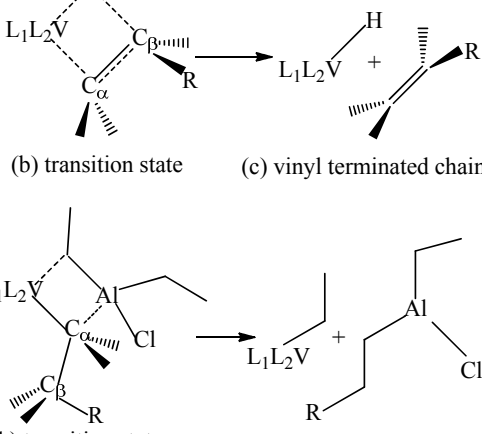

(b) transition state

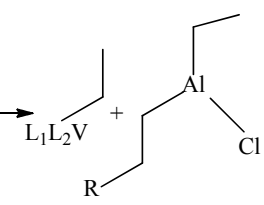

(c) AlREtCl
Scheme 5. Chain termination reactions ( $\mathrm{R}$ is the polymer chain).

shows three important chain transfer reactions: (1) $\beta$-hydride transfer to the monomer, (2) $\beta$-hydride elimination, and (3) chain transfer to aluminum.

As shown in Scheme 5, the $\beta$-hydride transfer to the monomer and $\beta$-hydride elimination pathways originate from the $\beta$-agostic polymer chain structure, while the chain transfer to aluminum pathway derives from the $\alpha$-agostic polymer chain structure. Therefore, it is necessary to consider the favorable product structure of the ethylene insertion reaction. As shown in Fig. 3, the most favorable reaction pathway is ethylene approaching the vanadium center and inserting into the polymer chain from the trans position with respect to the $\mathrm{N}$ atom. The direct product of ethylene insertion can be assumed to be the $\gamma$-agostic structure P1- $\boldsymbol{\gamma}$, which is unstable and will soon convert to P1- $\boldsymbol{\alpha}$ or P1- $\boldsymbol{\beta}$ because of the crowded environment around the vanadium center. P1- $\boldsymbol{\beta}$ was calculated to be slightly more stable than P1- $\boldsymbol{\alpha}$ (ca. $2.9 \mathrm{kcal} / \mathrm{mol}$ ), but its formation process may be more difficult. As described in Scheme 6, the polymer chain of $\mathbf{P 1}-\boldsymbol{\gamma}$ needs to rotate almost $180^{\circ}$ to form P1- $\boldsymbol{\beta}$, which is obviously unfavorable because the polymer chain and the ligands are eclipsing each other. The linear transit calculation result showed that the rotation process of the polymer chain needs to overcome an energy barrier of 8.5 $\mathrm{kcal} / \mathrm{mol}$. In short, P1- $\boldsymbol{\beta}$ has a more stable structure but P1- $\boldsymbol{\alpha}$ has a simpler formation process. Thus, it can be assumed that both $\alpha$-agostic and $\beta$-agostic structure polymer chains are present during polymerization.
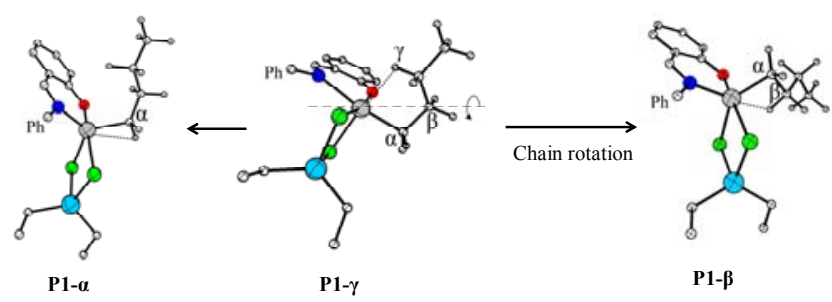

Scheme 6. Optimized geometries of ethylene insertion products.

\subsection{1. $\beta$-Hydride transfer to monomer}

If the product of ethylene insertion is $\beta$-agostic structure P1- $\boldsymbol{\beta}$, ethylene can approach the polymer chain and result in the formation of $\beta$-agostic $\pi$-complex $\mathbf{C}_{\text {ex }}$. The following process where the $\beta$-hydride of the polymer chain exchanges with the incoming ethylene is a chain termination reaction. After the $\beta$-hydride transfer to the monomer reaction, a vinyl-terminated polymer chain will be removed from the vanadium center and give rise to a new ethyl vanadium complex, which can potentially initiate another ethylene insertion reaction.

The intermediates and transition states of the $\beta$-hydride transfer to monomer reaction were obtained by optimization of the structures determined by linear transit calculations. The reaction coordinate of linear transit calculation was chosen as the distance between the $\beta$-hydride on the polymer chain and the carbon atom of the approaching ethylene monomer. As shown in Fig. 4, the vacant site of P1- $\boldsymbol{\beta}$ is hardly accessible for steric reasons. Consequently, the $\beta$-agostic $\pi$-complex $\mathbf{C}_{\mathbf{e x}}$ is only $0.9 \mathrm{kcal} / \mathrm{mol}$ more stable than the isolated molecules. The further approach of ethylene to $\mathbf{C}_{\mathbf{e x}}$ leads to the formation of transition state TS $_{\text {ex }}$ with an activation barrier of $10.4 \mathrm{kcal} / \mathrm{mol}$. The structure of $\mathbf{T S}_{\mathbf{e x}}$ shows evidence of $\mathrm{H}$-transfer from the polymer chain to ethylene: the olefin $\mathrm{C}-\mathrm{C}$ bond $(139.7 \mathrm{pm})$ is longer than that in the free ethylene molecule (133.2 pm) and the $\mathrm{C}_{\alpha}-\mathrm{C}_{\beta}$ bond (140.2 pm) of the polymer chain is shorter than that of P1- $\boldsymbol{\beta}$ (149.2 pm). Furthermore, TS exhibits a strong $\beta$-agostic interaction because of the short $\mathrm{H}_{\beta}-\mathrm{V}$ bond $(185.0$ pm) and long $\mathrm{C}_{\beta}-\mathrm{H}$ bond (148.9 pm). After $\beta$-hydride transfer to the monomer, a vinyl-terminated polymer chain will dissociate from the vanadium center, and then the remaining ethyl vanadium complex can serve as a new active species for ethylene polymerization. The final products (ethyl vanadium complex and vinyl-terminated polymer chain) are $10.5 \mathrm{kcal} / \mathrm{mol}$ higher in energy than the initial reactants before $\beta$-hydride exchange.

In contrast, similar formation of the $\beta$-agostic $\pi$-complex in the pathway with cationic active species $\mathbf{a} 4$ is much more facile, with an exothermic energy of $16.8 \mathrm{kcal} / \mathrm{mol}$. The energy barrier of the $\beta$-hydride transfer to monomer reaction with $\mathbf{a} 4$ is $17.6 \mathrm{kcal} / \mathrm{mol}$ (the energy of transition state of $\mathbf{a} 4$ is only 0.8 $\mathrm{kcal} / \mathrm{mol}$ higher than the isolated molecules and the total reaction is exothermic by about $2.1 \mathrm{kcal} / \mathrm{mol}$ ). Obviously, the

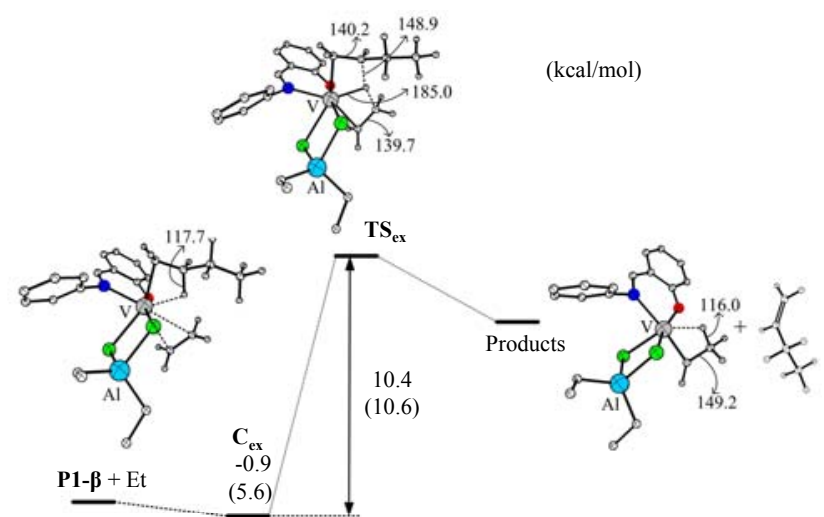

Fig. 4. Stationary points and schematic reaction profile for $\beta$-hydride transfer to the monomer. 
$\beta$-hydride transfer to monomer reaction pathway with active species $\mathbf{a} 4$ is much more favorable than that with active species a1. Therefore, it can be concluded that the unique bis(chlorine-bridged) structure in a1 may be the main reason for the difficulty of the $\beta$-hydride transfer to monomer reaction compared with active species a4.

\subsection{2. $\quad \beta$-Hydride elimination}

B-Hydride elimination can be considered as the extreme form of the $\beta$-agostic interaction in complex P1- $\boldsymbol{\beta}$, which is the $\beta$-hydride of the polymer chain completely transferred to the vanadium center. A metal hydride $C_{e l}$ and a vinyl-terminated polymer chain will then be produced. The $\beta$-hydride elimination energy profile evaluated by the linear transit method is shown in Fig. 5, where the reaction coordinate used for the calculation is the distance between the $\beta$-carbon of the growing polymer chain and the $\beta$-hydride. No obvious transition state was found in the $\beta$-hydride elimination energy profile. When the reaction coordinate is elongated to $5.0 \mathrm{pm}$, the energy of P1- $\boldsymbol{\beta}$ is $c a$. $34.4 \mathrm{kcal} / \mathrm{mol}$ higher than the initial structure. This significantly high energy required for the reaction indicates that $\beta$-hydride elimination is not a feasible pathway. For the ethylene polymerization pathway with cationic active species a4, $\beta$-hydride elimination is also a difficult chain transfer route, and is endothermic by $27.5 \mathrm{kcal} / \mathrm{mol}$.

\subsubsection{Chain transfer to aluminum}

Considering that excess $\mathrm{AlEt}_{2} \mathrm{Cl}$, as a cocatalyst, was used in the experimental investigations to attain high catalytic activity, polymer chain transfer to aluminum is another possible chain transfer pathway. The chain transfer to aluminum is assumed to occur via exchange of an ethyl group in $\mathrm{AlEt}_{2} \mathrm{Cl}$ with the polymer chain in the vanadium complex.

As shown in the energy diagram in Fig. 6, it is possible to assume a two-step mechanism for chain transfer to aluminum. Firstly, $\mathrm{AlEt}_{2} \mathrm{Cl}$ approaches the vanadium center of $\alpha$-agostic complex P1- $\boldsymbol{\alpha}$ to give intermediate $\mathbf{C}_{\text {ex-al }}$. Compared with the initial reactant P1- $\boldsymbol{\beta}$ in $\beta$-hydride elimination and $\beta$-hydride transfer to the monomer, the $\alpha$-agostic structure polymer chain in P1- $\boldsymbol{\alpha}$ more easily moves around the vanadium center to make room for the incoming $\mathrm{AlEt}_{2} \mathrm{Cl}$. As a result, in the chain

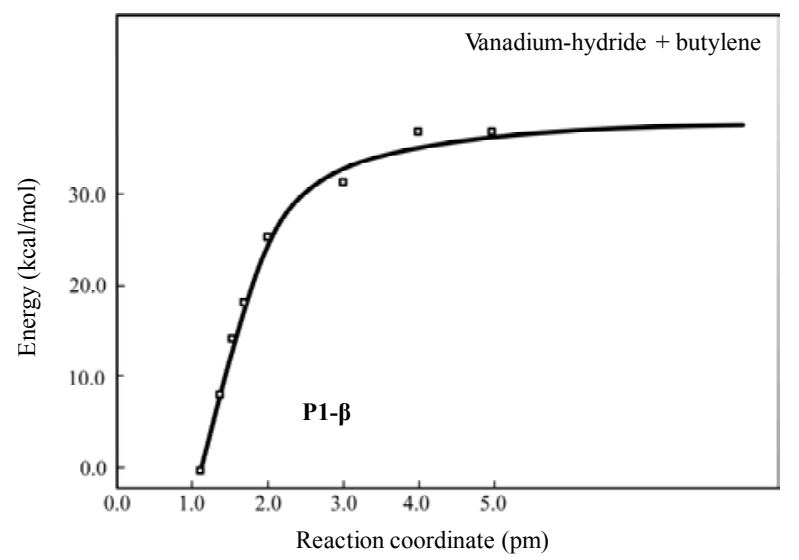

Fig. 5. Reaction energy profile of the $\beta$-hydride elimination.
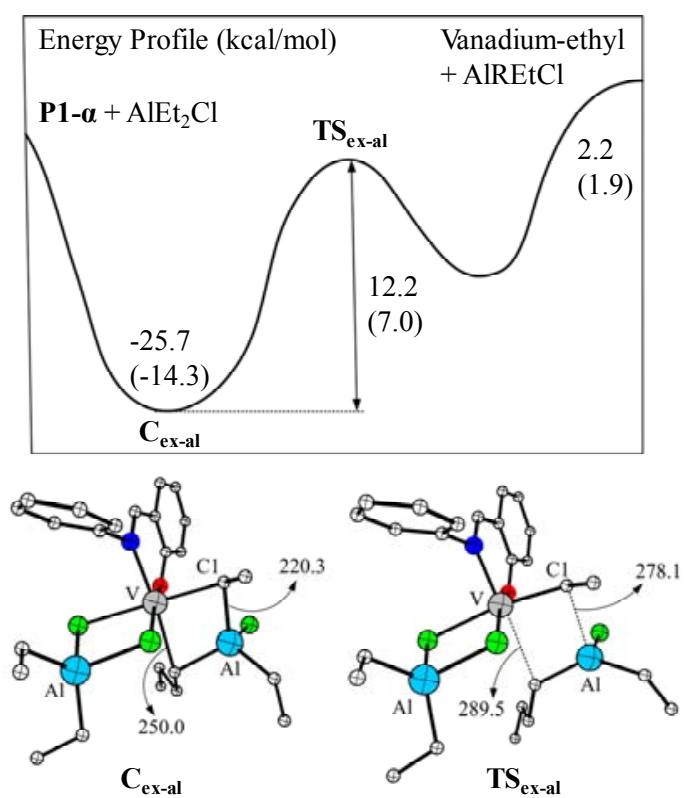

Fig. 6. Stationary points and schematic reaction profile for the chain transfer to $\mathrm{AlEt}_{2} \mathrm{Cl}$ reaction.

transfer to aluminum reaction, $\mathrm{AlEt}_{2} \mathrm{Cl}$ will approach the vanadium center from the vertical position of the salicylaldiminato plane. A linear transit calculation showed that this approaching process of $\mathrm{AlEt}_{2} \mathrm{Cl}$ required an energy barrier of about 8 $\mathrm{kcal} / \mathrm{mol}$, because of large steric repulsions between $\mathrm{AlEt}_{2} \mathrm{Cl}$ and the polymer chain or ligands of P1- $\boldsymbol{\alpha}$. Complex $\mathbf{C}_{\mathbf{e x}-\mathrm{al}}$ is about $25.7 \mathrm{kcal} / \mathrm{mol}$ more stable than the isolated molecules. The second step is the exchange of an ethyl group on $\mathrm{AlEt}_{2} \mathrm{Cl}$ with the polymer chain on the vanadium center of complex $\mathrm{C}_{\text {ex-al. }}$ We modeled the subsequent dissociation process by a linear transit calculation, where the $\mathrm{Al}-\mathrm{C}_{1}$ bond was chosen as the reaction coordinate. Transition state $\mathbf{T S} 2$ ex-al was obtained by full transition state optimization of the structure obtained from this linear transit calculation. The calculated energy barrier for the polymer chain transfer from the vanadium center to $\mathrm{AlEt}_{2} \mathrm{Cl}$ process was $12.2 \mathrm{kcal} / \mathrm{mol}$. After the polymer chain completely transferred to aluminum, AlREtCl (R represents the polymer chain) will dissociate from the vanadium center to give an ethyl vanadium complex, which can initiate further ethylene polymerization. The whole chain transfer to aluminum reaction is endothermic by $2.2 \mathrm{kcal} / \mathrm{mol}$.

Comparing the chain propagation reactions, the chain transfer to aluminum reaction has a lower activation barrier than the ethylene insertion reaction. However, considering the whole reaction process, the chain transfer to aluminum reaction is endothermic, while the ethylene insertion reaction is highly exothermic $(27.1 \mathrm{kcal} / \mathrm{mol})$. This indicates that the chain transfer to aluminum is not competitive with the ethylene insertion step, and this catalyst system can give high molecular mass polyolefins.

For the chain transfer to aluminum reaction with cationic active species a4, the product $\mathbf{C}_{\mathbf{e x}-a l}$ of the $\mathrm{AlEt}_{2} \mathrm{Cl}$ approach process is $21.1 \mathrm{kcal} / \mathrm{mol}$ more stable than the ethylene insertion $\alpha$-agostic product P1- $\boldsymbol{\alpha}$. The subsequent chain transfer 
process needs to overcome an energy barrier of $16.9 \mathrm{kcal} / \mathrm{mol}$, which is similar to the chain transfer to monomer reaction (17.6 kcal/mol). The total chain transfer to aluminum reaction is endothermic by $3.8 \mathrm{kcal} / \mathrm{mol}$. Considering that chain transfer to the monomer is an exothermic reaction, the most favorable chain transfer pathway for ethylene polymerization by active species a4 is chain transfer to the monomer, which is inconsistent with the experimental results. This further excludes the possibility that cationic species $\mathbf{a} 4$ is the favorable active form in this catalytic system.

Comparing the three chain transfer pathways for ethylene polymerization by active species a1, the process of chain transfer to aluminum is the simplest, because it originates from P1- $\boldsymbol{\alpha}$, whose formation process does not involve costly rotation of the polymer chain. The activation energy barrier of chain transfer to aluminum is similar to that of $\beta$-hydride transfer to the monomer but much lower than that of the $\beta$-hydride elimination reaction. Furthermore, the formation process of the $\pi$-complex of the chain transfer to aluminum reaction is highly exothermic, and the endothermicity of the total reaction is significantly lower than that of the other two reactions. As a result, it is concluded that chain transfer to aluminum is the main chain transfer pathway for this catalytic system. This is in good agreement with experimental observations that the molecular mass of the resultant polymer decreases with increasing $\mathrm{Al} / \mathrm{V}$ ratio and the end group of the polymer chain is saturated. This is also indirect evidence for our conclusion that bimetallic neutral species $\mathbf{a} \mathbf{1}$ is the most likely catalytically active species in this vanadium(III) catalytic system.

\section{Conclusions}

DFT calculations were performed for ethylene polymerization catalyzed by vanadium(III) complexes bearing salicylaldiminato ligands. These calculations focused on the most likely active species for the catalytic reaction, and involved ethylene insertion and chain transfer mechanisms. By comparing the results of theoretical calculations and previous experimental results, especially regarding the crucial role of the $\mathrm{AlEt}_{2} \mathrm{Cl}$ cocatalyst, we propose a neutral bimetallic active species $\mathbf{a} 1$ for this vanadium catalytic system. The active species a1 contains two $\mathrm{V}-\mathrm{Cl}-\mathrm{Al}$ bridging bonds, which provides a reasonable explanation for the important effect of $\mathrm{AlEt}_{2} \mathrm{Cl}$ on ethylene polymerization. Then, this assumption was verified for both the formation process of the active species and the catalytic mechanism of ethylene polymerization.

Bridging an $\mathrm{AlEt}_{2} \mathrm{Cl}$ moiety by two $\mathrm{Al}-\mathrm{Cl}-\mathrm{V}$ bridging bonds helps to maintain the octahedral configuration of active species a1, and decreases the electron deficiency and coordinative unsaturation of the vanadium center, thereby stabilizing the active species. As a result, the formation of neutral bimetallic species a1 is more energetically favorable than the other possible active species. Additionally, bridging the $\mathrm{AlEt}_{2} \mathrm{Cl}$ moiety also facilitates ethylene insertion into the polymer chain. Consequently, the energy barrier of the ethylene insertion process with $\mathbf{a} 1$ is found to be significantly lower than the energy barriers with other possible neutral species. Moreover, the formation processes of neutral active species are energetically more favorable than those of cationic active species. The energetic superiority of both the formation and ethylene insertion processes supports our assumption of bimetallic active species a1. In addition, we performed comparative calculations of the chain transfer mechanisms involved with a1 and a4. The dominant chain transfer reaction with neutral active species $\mathbf{a} \mathbf{1}$ is chain transfer to aluminum, which is in good agreement with experimental observations. In contrast, the theoretical result with cationic active species $\mathbf{a} 4$ is inconsistent with previous experimental results. This supports that the active species is bimetallic species a1.

This investigation has provided insight into the structure of the vanadium active species for ethylene polymerization, the main steps of the olefin polymerization mechanism, and the role of cocatalysts in the polymerization. Moreover, our active species model helps to rationalize previous experimental findings and provides important information for further investigations of the design of efficient vanadium catalysts.

\section{Acknowledgments}

We are grateful to Computing Center of Jilin Province for essential support.

\section{References}

[1] Ziegler K. Angew Chem, 1964, 76: 545

[2] Natta G. Angew Chem, 1956, 68: 393

\section{Graphical Abstract}

Chin. J. Catal., 2015, 36: 657-666 doi: 10.1016/S1872-2067(14)60271-0

Theoretical investigation of the mechanism of ethylene polymerization with salicylaldiminato vanadium(III) complexes

Yongxia Wang, Minghui Zuo, Yuesheng Li*

Changchun Institute of Applied Chemistry, Chinese Academy of Sciences;

Mudanjiang Normal University; Tianjin University

Density functional theory calculations were performed to investigate the mechanism of ethylene polymerization with salicylaldiminato V(III) complexes. A neutral bimetallic species containing two Al-Cl-V bridging bonds proved to be the most reasonable V(III) active species.

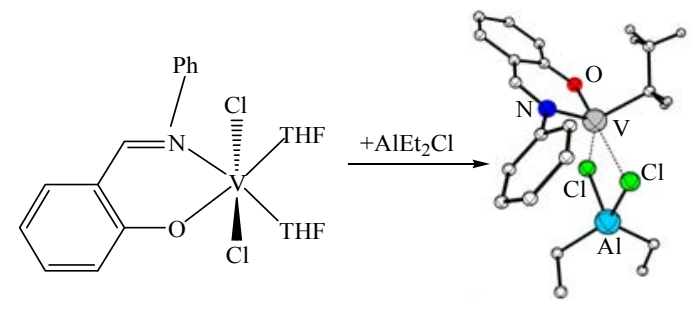


[3] Carrick W L.J Am Chem Soc, 1958, 80: 6455

[4] Carrick W L, Kluiber R W, Bonner E F, Wartman L H, Rugg F M, Smith J J. J Am Chem Soc, 1960, 82: 3883

[5] Natta G, Pasquon I, Zambelli A. J Am Chem Soc, 1962, 84: 1488

[6] Natta G, Zambelli A, Lanzi G, Pasquon I, Mognaschi E R, Segre A L, Centola P. Makromol Chem, 1965, 81: 161

[7] Zambelli A, Pasquon I, Signorini R, Natta G. Makromol Chem, 1968, 112: 160

[8] Doi Y, Kinoshita J, Morinaga A, Keii T. J Polym Sci A, 1975, 13: 2491

[9] Christman D L, Keim G I. Macromolecules, 1968, 1: 358

[10] Doi Y, Suzuki S, Soga K. Macromolecules, 1986, 19: 2896

[11] Doi Y, Tokuhiro N, Nunomura M, Miyake H, Suzuki S, Soga K. In: Kaminsky W, Sinn H Eds. Transition Metals and Organometallics as Catalysts for Olefin Polymerization. Berlin: Springer-Verlag, 1988. 379

[12] Adisson E, Deffieux A, Fontanille M, Bujadoux K. J Polym Sci A, 1994, 32: 1033

[13] Tomov A K, Gibson V C, Zaher D, Elsegood M R J, Dale S H. Chem Commun, 2004: 1956

[14] Wang W, Nomura K. Macromolecules, 2005, 38: 5905

[15] Redshaw C, Rowan M A, Homden D M, Dale S H, Elsegood M R J, Matsui S, Matsuura S. Chem Commun, 2006: 3329

[16] Zambelli A, Sessa I, Grisi F, Fusco R, Accomazzi P. Macromol Rapid Commun, 2001, 22: 297

[17] Nomura K, Zhang S. Chem Rev, 2011, 111: 2342

[18] Wu J Q, Pan L, Hu N H, Li Y S. Organometallics, 2008, 27: 3840

[19] Wu J Q, Pan L, Li Y G, Liu S R, Li Y S. Organometallics, 2009, 28: 1817

[20] Wu J Q, Pan L, Liu S R, He L P, Li Y S. J Polym Sci A, 2009, 47: 3573

[21] Wu J Q, Mu J S, Zhang S W, Li Y S. J Polym Sci A, 2010, 48: 1122

[22] Doi Y, Suzuki S, Hizai G, Soga K. In: Quirk R P Ed. Transition Metal Catalyzed Polymerization. Cambridge: Cambridge University Press, 1988. 182

[23] Evens G G, Pijpers E M J, Seevens R H M. In: Quirk R P Ed. Transi- tion Metal Catalyzed Polymerization. Cambridge: Cambridge University Press, 1988. 782

[24] Coles M P, Gibson V C. Polym Bull, 1994, 33: 529

[25] Niu S Q, Hall M B. Chem Rev, 2000, 100: 353

[26] Lohrenz J C W, Woo T K, Fan L Y, Ziegler T. J Organomet Chem, 1995, 497: 91

[27] Ziegler T. Chem Rev, 1991, 91: 651

[28] Liu Z, Zhong L, Yang Y, Cheng R H, Liu B P. J Phys Chem A, 2011, 115: 8131

[29] Kawamura-Kuribayashi H, Koga N, Morokuma K. J Am Chem Soc, 1992, 114: 8687

[30] Kawamura-Kuribayashi H, Koga N, Morokuma K. J Am Chem Soc, 1992, 114: 2359

[31] Shiga A, Kawamura H, Ebara T, Sasaki T, Kikuzono Y. J Organomet Chem, 1989, 366: 95

[32] Prosenc M H, Janiak C, Brintzinger H H. Organometallics, 1992, 11: 4036

[33] Wang D Q, Tomasi S, Razavi A, Ziegler T. Organometallics, 2008, 27: 2861

[34] Cramer C J, Truhlar D G. Phys Chem Chem Phys, 2009, 11: 10757

[35] Cavallo L, Guerra G, Vacatello M, Corradini P. Macromolecules, 1991, 24: 1784

[36] Bühl M. Organometallics, 1999, 18: 4894

[37] te Velde G, Bickelhaupt F M, Baerends E J, Guerra C F, Van Gisbergen S J A, Snijders J G, Ziegler T. J Comput Chem, 2001, 22: 931

[38] Becke A D. Phys Rev A, 1988, 38: 3098

[39] Perdew J P. Phys Rev B, 1986, 33: 8822

[40] Zhao Y, Truhlar D G. J Chem Phys, 2006, 125: 194101

[41] Reiher M, Salomon 0, Hess B A. Theor Chem Acc, 2001, 107: 48

[42] Cossee P. J Catal, 1964, 3: 80

[43] Sinn H, Kaminsky W, Vollmer H J, Woldt R. Angew Chem Int Ed Engl, 1980, 19: 390

[44] Kaminsky W, Miri M, Sinn H, Woldt R. Makromol Chem Rapid Commun, 1983, 4: 417

\title{
水杨醛亚胺钒(III)化合物催化乙烯聚合反应机理
}

\author{
王永霞 ${ }^{\mathrm{a}}$, 左明辉 ${ }^{\mathrm{b}}$, 李悦生 ${ }^{\mathrm{a}, \mathrm{c},{ }^{*}}$ \\ $\mathrm{a}$ 中国科学院长春应用化学研究所高分子物理与化学国家重点实验室, 吉林长春 130022

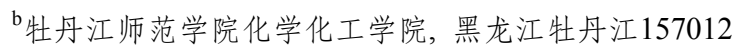 \\ ${ }^{\mathrm{c}}$ 天津大学材料科学与工程学院, 天津 300072
}

\begin{abstract}
摘要: 钒系烯烃聚合催化剂在工业上有着不可替代的位置, 它可用于制备高活性窄分布的聚合物、乙烯与 $\alpha$-烯烃共聚物和间规聚 丙烯等. 但由于实验手段难以确定钥催化剂活性物种的结构, 进一步对催化机理的确认及催化剂结构的改进十分困难. 本文运用 密度泛函方法对水杨醛亚胺钒配合物催化乙烯聚合的活性物种结构进行了理论研究. 对多种活性物种模型的比较研究结果表明, 对此催化反应最有利的活性物种为中性双金属物种 $\mathrm{a} 1, \mathrm{a} 1$ 结构中包含两个连接铝原子与钒中心的氯桥结构. 研究同时表明, 助催 化剂 $\mathrm{AlEt}_{2} \mathrm{Cl}$ 的存在不仅加速了钒配合物前体的烷基化反应, 同时其对活性物种 $\mathrm{a} 1$ 结构中氯桥的形成至关重要. 最后还研究了该 催化体系的链终止反应机理.
\end{abstract}

关键词: 量子化学计算; 密度泛函理论; 烯烃聚合; 钒; 催化机理

收稿日期: 2014-11-07. 接受日期: 2014-12-12. 出版日期: 2015-04-20.

*通讯联系人. 电话: (0431)85262124; 传真: (0431)85262039; 电子信箱: ysli@ciac.ac.cn

基金来源：国家自然科学基金(21104081, 21234006).

本文的英文电子版由Elsevier出版社在ScienceDirect上出版(http://www.sciencedirect.com/science/journal/18722067). 